\title{
CFD EVALUATION OF LEAN-DIRECT INJECTION COMBUSTORS FOR COMMERCIAL SUPERSONICS TECHNOLOGY
}

\author{
Kumud Ajmani \\ Vantage Partners, LLC \\ Cleveland, Ohio, USA \\ Clarence T. Chang \\ NASA Glenn Research Center \\ Cleveland, Ohio, USA
}

\author{
Phil Lee \\ Woodward FST, Inc \\ Zeeland, MI, USA \\ Maureen T. Kudlac \\ NASA Glenn Research Center \\ Cleveland, Ohio, USA
}

An overview is given of an effort that focused on using CFD analysis to complement design and configuration definition of Lean-Direct Injection (LDI) combustion concepts for NASA's Commercial Supersonic Transport (CST) program. The National Combustion Code (OpenNCC) was used to perform non-reacting and twophase reacting flow computations for second and third generation LDI configurations at CST cruise conditions. All computations were performed with a consistent approach of mesh-generation, spray modeling, ignition and kinetics modeling. Emissions (EINOx) characteristics were predicted for CST cruise conditions, and compared with emissions data from experimental measurements to evaluate the fidelity of the CFD modeling approach to predict emissions changes in response to changes in supersonic cycle conditions.

\section{INTRODUCTION}

The three main environmental challenges to the Commercial Supersonic Transport (CST) program, as identified by NASA are low-boom, noise, and emissions $[1,2]$. The FAA has been directed to look at standards for actually flying CST, and the FAA has stated that new rules are needed to certify CST aircraft. In order to accomplish this, the FAA is soliciting input from NASA on 'how to determine' emissions standards for CST. This paper describes an effort to determine the emissions characteristics of two separate LDI flametubes, both of which were originally designed for subsonic applications under NASA's Environmentally Responsible Aviation (ERA or N+2) and N+3 programs, respectively[3,4]. The current generation LDI-3 design was developed for the N+3 program to improve upon the operability, stability and emissions of a previous generation LDI-2 design developed for the ERA program [5].

The National Combustor Code (OpenNCC) was used to perform CFD evaluations of LDI-2 [5] and LDI-3 injector [6] designed by Woodward, FST Inc. (WFST). Reacting flow simulations were performed at supersonic cruise conditions for two separate flametube configurations. A finite-rate reduced-kinetics model and Lagrangian-spray modeling (for the liquid phase droplets) were used within OpenNCC CFD to compute heat release and NOx emissions. This paper reports OpenNCC computations for a thirteen-element LDI-2 flametube array and a nineteen-element LDI-3 flametube array (two seven-element modules and one five-element module), Both configurations underwent performance and emissions testing at NASA Glenn Research Center's CE-5 medium pressure facility.

\section{LEAN-DIRECT INJECTION FLAMETUBE DESIGNS}
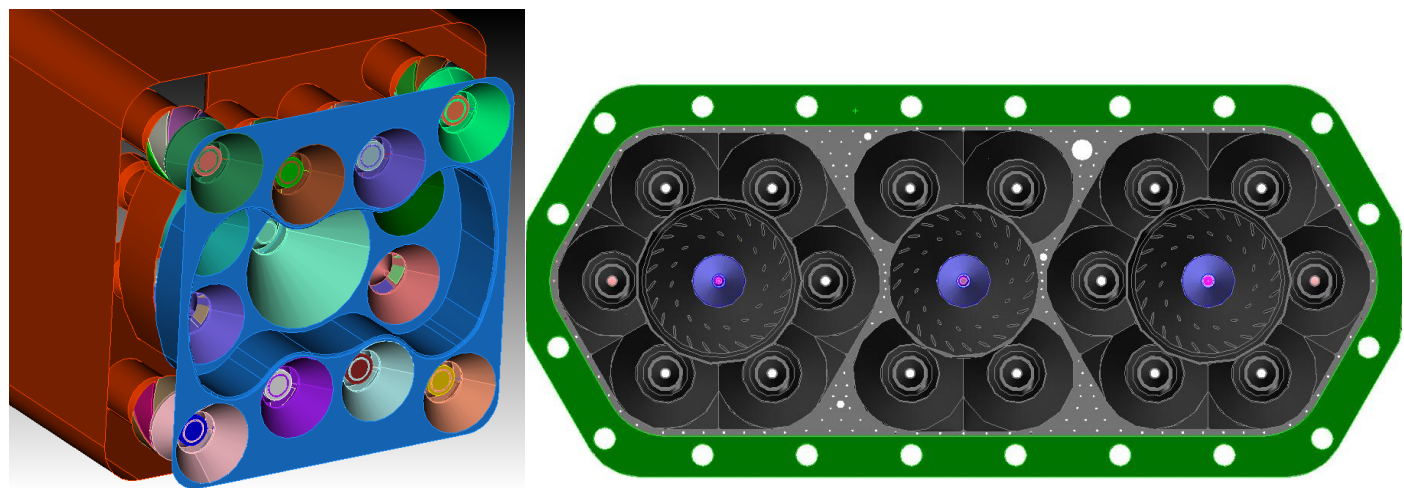

Figure 1. Dome layout of LDI-2 (left) and LDI-3 (right) flame-tube design (Woodward FST)

Figure 1 shows the two different lean-direct injection (LDI) flame-tubes which were designed by Woodward FST, Inc (WFST) for NASA's N+2 and N+3 programs, respectively. The two different designs are referred to in this 
paper as LDI-2 and LDI-3, respectively. Both designs were tested by WFST and NASA GRC at different operating (subsonic and supersonic cycle) conditions. The major changes between the LDI-2 and LDI-3 designs were driven by requirements of a smaller core, higher operating pressure ratio, better thermal management of fuel and injector integration, and reduction in overall emissions. The LDI-2 design consists of thirteen injector elements, with five elements (including the central pilot element) recessed from the dome [5]. The LDI-3 design consists of three injector 'cups', where each cup consists of multiple (four or six) main injectors surrounding a central pilot injector [6].

\section{CFD Evaluation of LDI-2 Configurations with OpenNCC}

Figure 2 shows CFD results for the LDI-2 design, as evaluated for a supersonic cruise condition with the OpenNCC code. The operating conditions for this computation were based on a NASA GRC developed cycle for CST aircraft: Mach $=1.7$, Altitude $=15.5 \mathrm{~km}, \mathrm{P} 3=15 \mathrm{bar}, \mathrm{T} 3=920 \mathrm{~K}, \Delta \mathrm{p}=5 \%$, global phi=0.43, dome phi=0.56 with $24 \%$ cooling air, T4=2085K. The CFD predicts that the fuel-air mixing is complete within $100 \mathrm{~mm}$ of the dome and the combustion is complete within 50mm of the dome. The CFD predicted EINOx for this cycle condition was 30. The CST program's emissions goal for a typical cruise condition is to attain an EINOx of 5. Note that the CFD predicted EINOx of 30 is for an LDI-2 design that was extensively optimized for subsonic aircraft conditions under NASA's ERA (N+2) program. It is reasonable to expect that there is much room for improvement in emissions and performance of this design after injector and hardware optimizations are performed for supersonics cycle conditions.

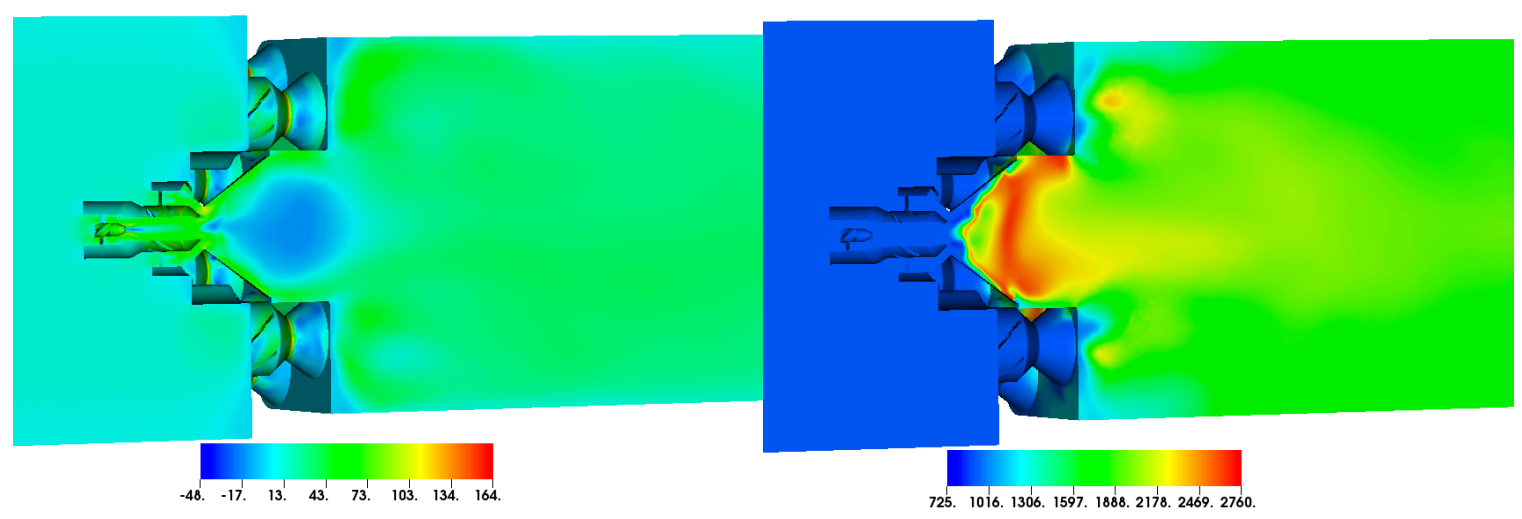

Figure 2. Axial velocity (left, $\mathrm{m} / \mathrm{s}$ ) and temperature (right, K) contours for LDI-2 (OpenNCC CFD)

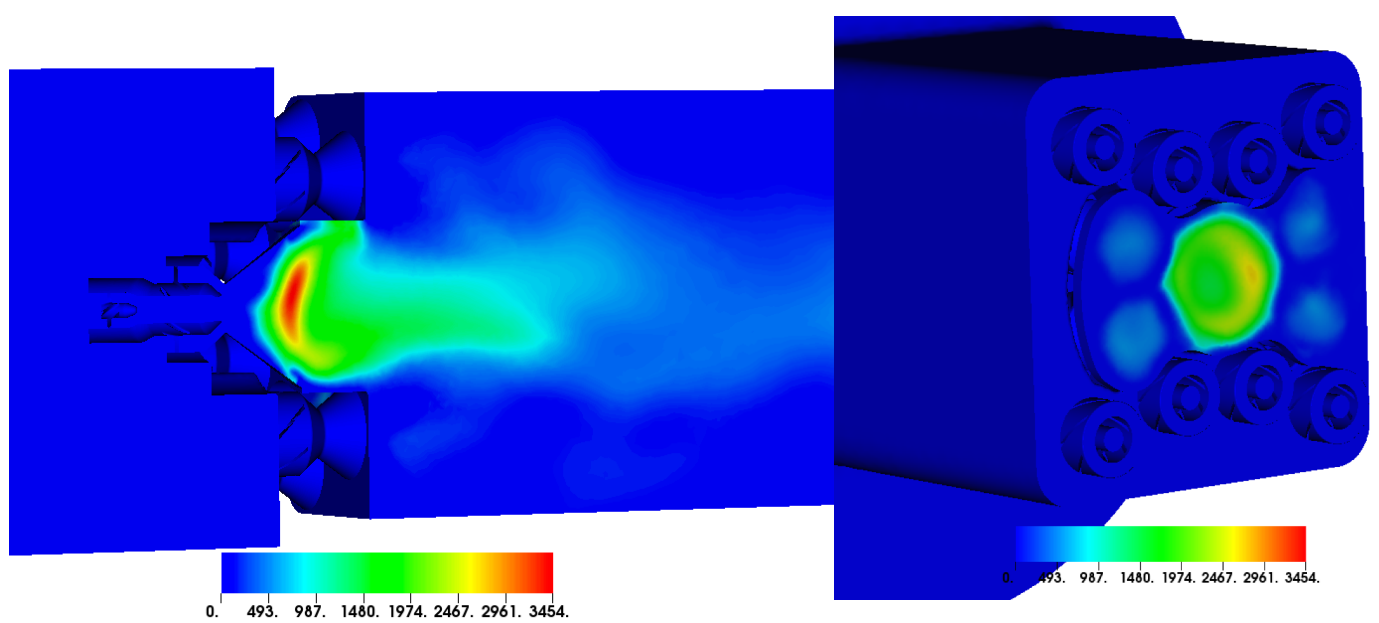

Figure 3. NO contours (ppm) for LDI-2 predicted by OpenNCC CFD (CST cruise)

Figure 3 shows the CFD predicted NOx contours for the CST cruise conditions corresponding to figure 2. The CFD predicts that a majority of the EINOx for the LDI-2 design is being produced by the central pilot injector, and suggests that improvements to the pilot injector design could considerably impact the NO produced in the CST cycle. Some of the optimization possibilities are:

1. Decrease the swirler angle of the axially swirling airflow blade passages of the pilot injector

2. Change fuel-injector for Pilot injector from airblast (dual axial-bladed swirlers for airflow) to simplex pressure-atomizer (single axial-bladed swirler for airflow) 
3. Trade 'low-power operability' margin for EINOx by decreasing (or eliminating) the recess for the pilot and its four main injectors from the dome. Recessing the injectors provides better flame-holding at low-power conditions, but also increases residence time, which increases EINOx production. The current (recessed pilot) and alternative (non-recessed or 'flat dome') configurations are shown in figure 4. The 'flat dome' configuration was shown to reduce EINOx at subsonic cruise conditions when tested under the N+2/ERA program [5].

Figure 4. Optimization of LDI-2 Pilot Injector for CST. Recessed (left) and 'flat dome' (right)
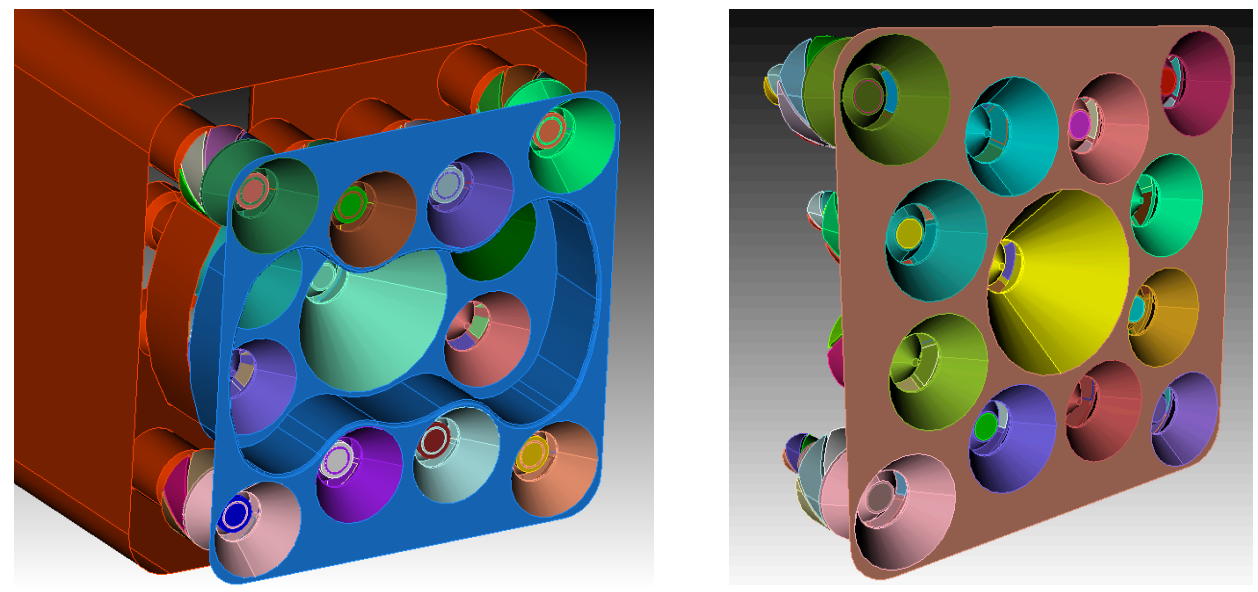

\section{CFD Evaluation of LDI-3 Configurations with OpenNCC}

Figure 5 shows a representation of a newly designed pre-filming injector for an LDI-3 configuration, as integrated into a seven-element cup consisting of six pre-filming element (mains) and one central pilot element. Each pre-filming main injection element consist of a plain-jet orifice that injects fuel tangentially along the pre-filmer surface. Swirling airflow created by "inner" axially-bladed air-swirlers transports the fuel sheet downstream. The fuel sheet exiting the pre-filmer is broken up by the swirling airflow created by the "outer" axially bladed swirlers. The blade turning angles for the inner and outer swirlers are typically 60 and 45 degrees, respectively. Integration of multiple main injection elements and a central pilot injector is used to create multi-element cups consisting of five or seven elements. An integrated fuel stem was designed by Woodward FST to simplify the fueling of multiple elements for each cup and provide potentially better thermal management of fuel for the LDI-3 designs.
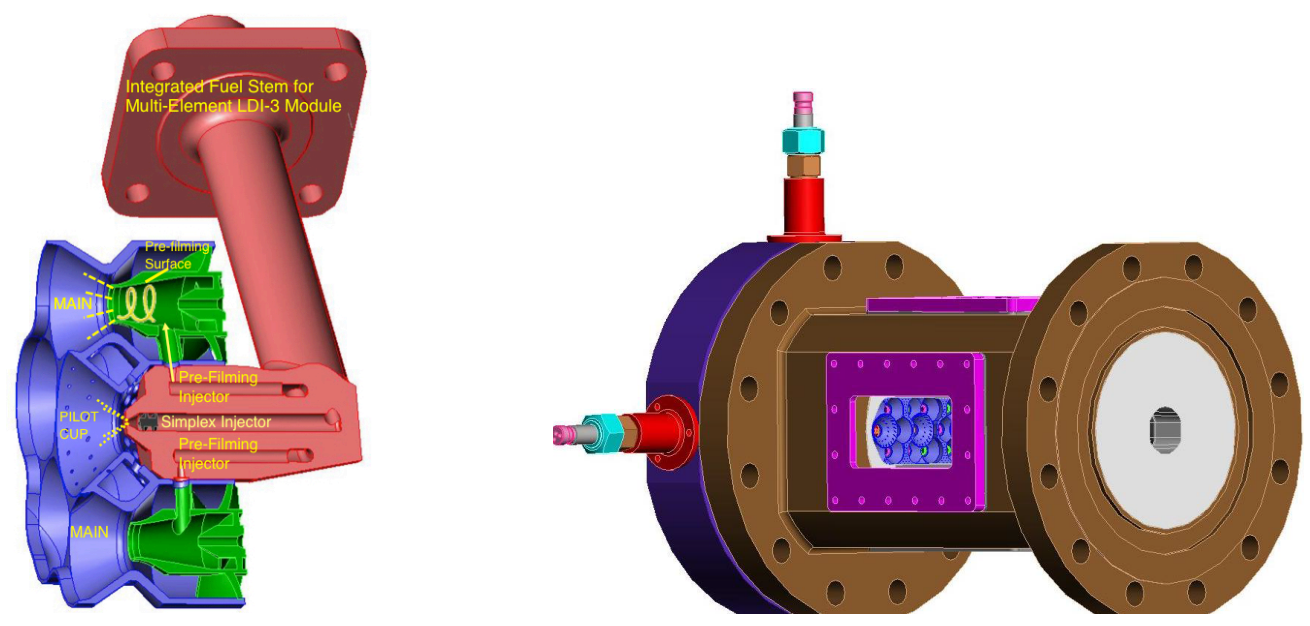

Figure 5. Dome-layout with main- and pilot-injector elements for a 7-element LDI-3 injector module (left) and the 19element (3-Cup) flametube mounted in NASA Glenn CE-5 test facility (right) 
Testing of the 3-cup, 19-element configuration was performed in the NASA Glenn CE-5 medium pressure flametube shown in Figure 2. The flametube has a cast ceramic liner which approximates an adiabatic boundary condition. This facility can supply non-vitiated air preheated to $922 \mathrm{~K}$ at pressures up to $19.0 \mathrm{bar}$, which allows it to reach the desired cycle P3 and T3 for supersonic cruise. However, the facility could not reach the desired dome equivalence ratio (and T4) when adjusted for 15\%-24\% liner cooling. Hence, the NOx emissions at supersonic cruise were obtained by extrapolating the EINOx vs T4 correlation curve-fit derived from CE- 5 experimental data. The extrapolated values of EINOx were estimated to be $25 \mathrm{~g} / \mathrm{kg}(15 \%$ liner cooling, T4 = 1990K) and $40 \mathrm{~g} / \mathrm{kg}(24 \%$ liner cooling, T4=2085K) [6].

This section describes OpenNCC CFD results of a nineteen element, three-module injector assembly, as tested in a flametube configuration at NASA Glenn. A part of the surface mesh corresponding to the global volume mesh of 21.34million all-tetrahedral elements is shown in figure 6. Inflow boundary conditions (specified $P_{t}, T_{t}$ ) were set corresponding to $P_{3}=15$ bar and $T_{3}=920 K$, respectively. The outflow boundary back-pressure was specified from the $P_{3}$ and the pressure-drop $(\Delta \mathrm{p}=5 \%)$. Adiabatic, no-slip boundary conditions were specified on all solid surfaces.

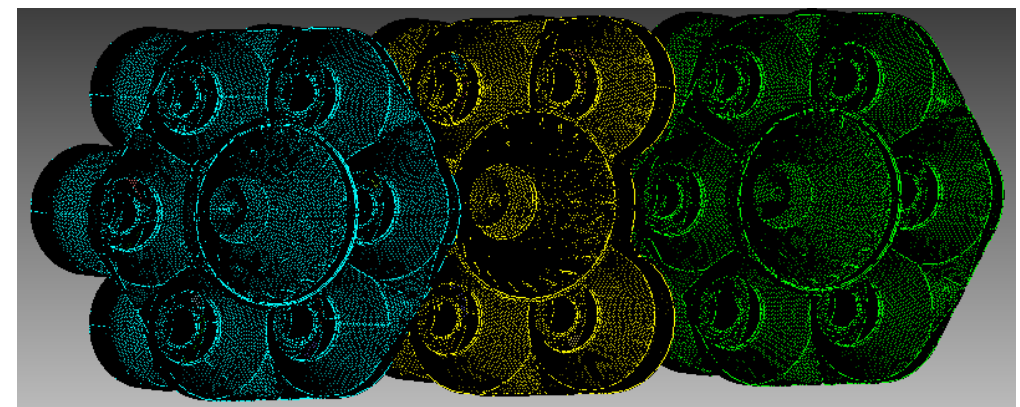

Figure 6. Surface-mesh for CFD evaluation of the 3-cup (19-injector) LDI-3 Flametube

Non-reacting RANS computations with 4-stage explicit Runge-Kutta integration were first performed, and typical convergence was obtained within 100,000 iterations using a $\mathrm{CFL}=0.95$. The RANS solution was used to compute the effective area predicted by OpenNCC, and also used as an initial solution for performing 10,000 timesteps (10m-s of physical time) of a non-reacting Time-Filtered Navier Stokes (TFNS) time-accurate simulation. This is was followed by reacting TFNS simulations, which included fuel-injection modeling with lagrangian spray [9], ignition of fuel-air mixture with an ignition source term, and finite-rate chemistry modeling of combustion with a 14-species, 18-step chemistry mechanism [10]. Complete details of the OpenNCC CFD methodology and physical models are available in $[7,8]$.

The Open-NCC CFD results were post-processed to produce contour plots at several cross-sectional slices (see figure 7). The first cross-sectional slice is across the horizontal (long) axis of the flametube is designated section-AA and includes alternating main injectors and pilot injectors. Three other slices taken across the vertical (short) axis of the flametube are denoted as sections $\mathrm{BB}, \mathrm{CC}$ and $\mathrm{DD}$, one slice through each pilot element. The respective swirl orientation of the primary airflow through each injection element is labeled as ' $\mathrm{CW}$ ' (clockwise) and ' $\mathrm{CCW}$ ' (counterclockwise) when looking upstream towards the dome face.



Figure 7. Cross-sectional planes for Open-NCC CFD Contours - sections AA, BB, CC and DD

Figure 8 shows the computed axial velocity contours at various cross-sections of the 19-element flametube assembly. The results are a time-average of the final 2600 time-steps (2.6m-s physical time), which corresponds to the final flow-through cycle of the OpenNCC computations. Figure 8 shows the presence of fairly large central recirculation zones (CRZs) behind each of the central pilot injectors, and much smaller CRZs behind each main injector. The presence of CRZs is desirable for flame-holding and stability, but can have a negative impact on emissions performance due to increased residence time. 

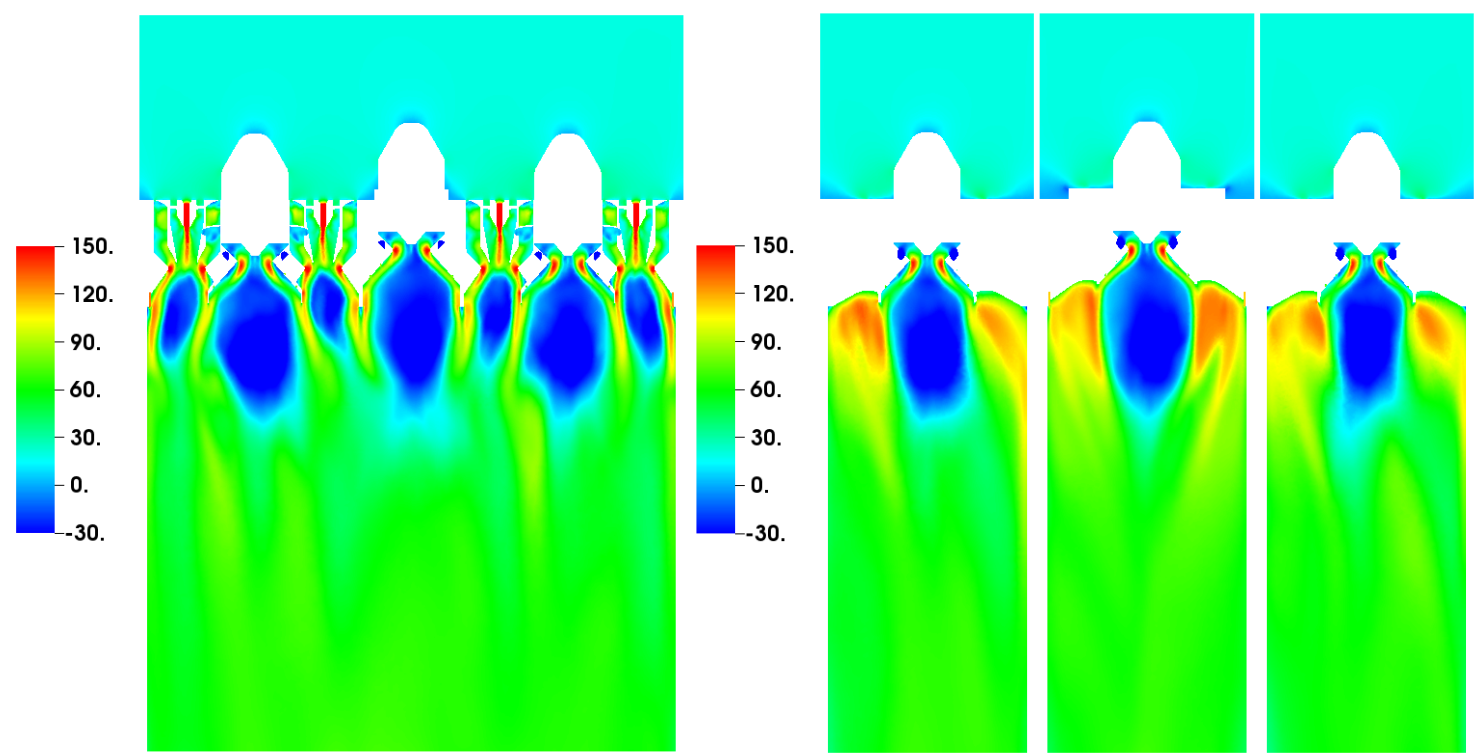

Figure 8. Axial Velocity $(\mathrm{m} / \mathrm{s})$ contours at several cross sections for LDI-3 (left: horizontal slice along length of flametube, AA; right: vertical slices through each pilot injector, DD, BB, CC)

Figure 9 shows the time-averaged, temperature contours computed with OpenNCC TFNS. The flame zones behind several of the main injectors are particularly large, and extend to almost $75 \mathrm{~mm}$ downstream of the dome face (half of the flametube length of $150 \mathrm{~mm}$ ) (figure 9, left). The center-cup pilot injector (figure 9, right, section BB) shows a significantly cooler flame as compared to the two other pilot injectors. This can partly be explained by the small but aerodynamically significant recess of the center-cup pilot, which creates a different evaporation and air-fuel mixing profile for the central, 5-element cup as comparted to the two outlying 7-element cups. the In addition, there is a significant asymmetry of the flame structure about the centerline of each pilot injector, particularly behind the pilot injectors of each 7-element cup (figure 9, right; section DD, CC). This asymmetry exists because of the alternating clock-wise and counter clock-wise orientation of the air-swirlers (see figure 7) for the main injectors surrounding each central pilot injector. An updated, next-generation swirler design (not shown here), where all the swirlers for the main injectors within each cup were clocked in the same direction, was shown to considerably improve this asymmetric combustion behavior.

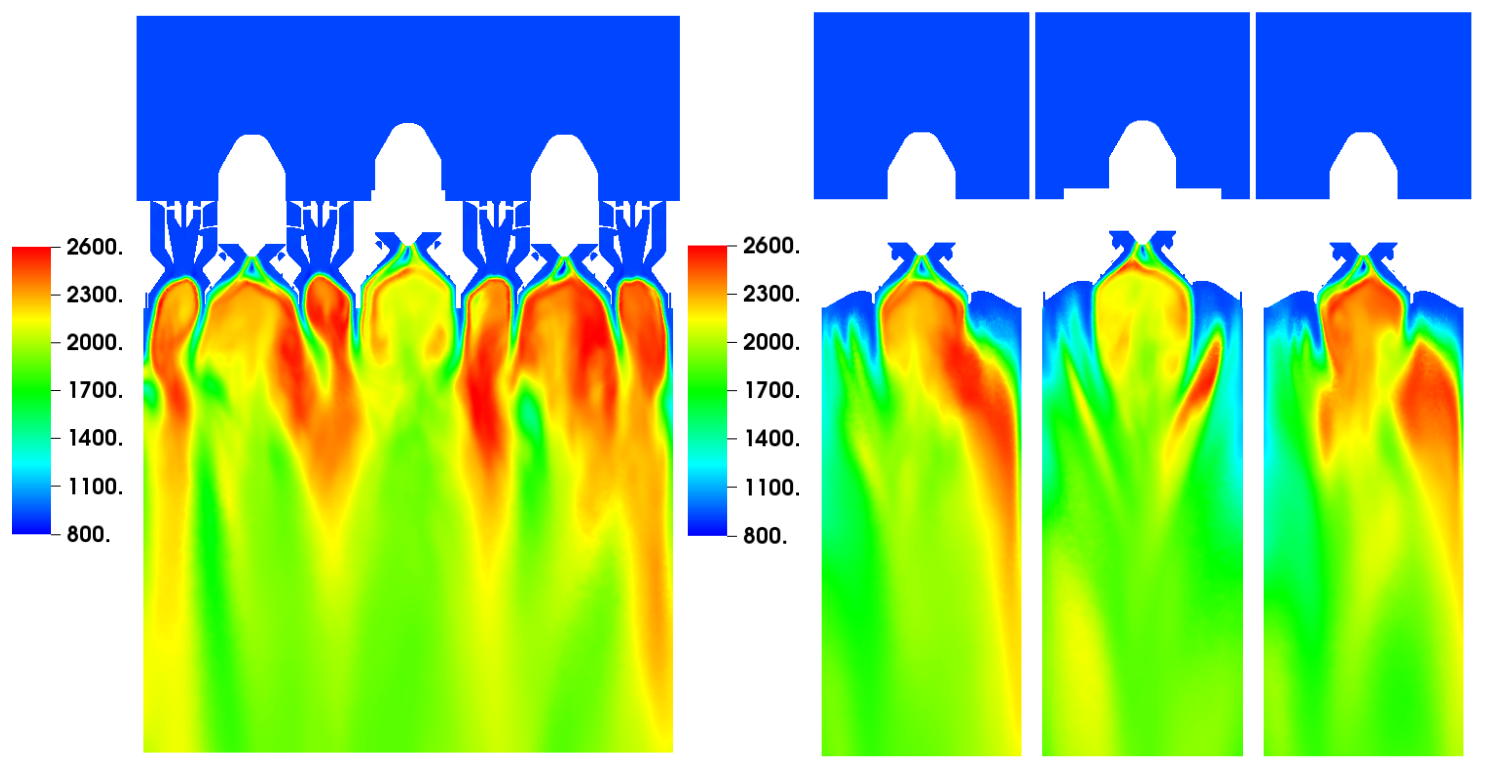

Figure 9. Temperature $(\mathrm{K})$ contours at several cross sections for LDI-3 (left: horizontal slice along length of flametube, AA; right: vertical slices through each pilot injector, DD, BB, CC) 
Figure 10 shows the time-averaged, NO contours corresponding to the temperature contours shown in figure 9. The pilot injectors of the two outer 7-element cups (section DD, CC) produce the greatest NO near the dome, immediately downstream of the hottest regions of the flame. The main injectors produce much less NO, and it tends to be mostly produced in the downstream regions of the flametube, farther away from the dome.
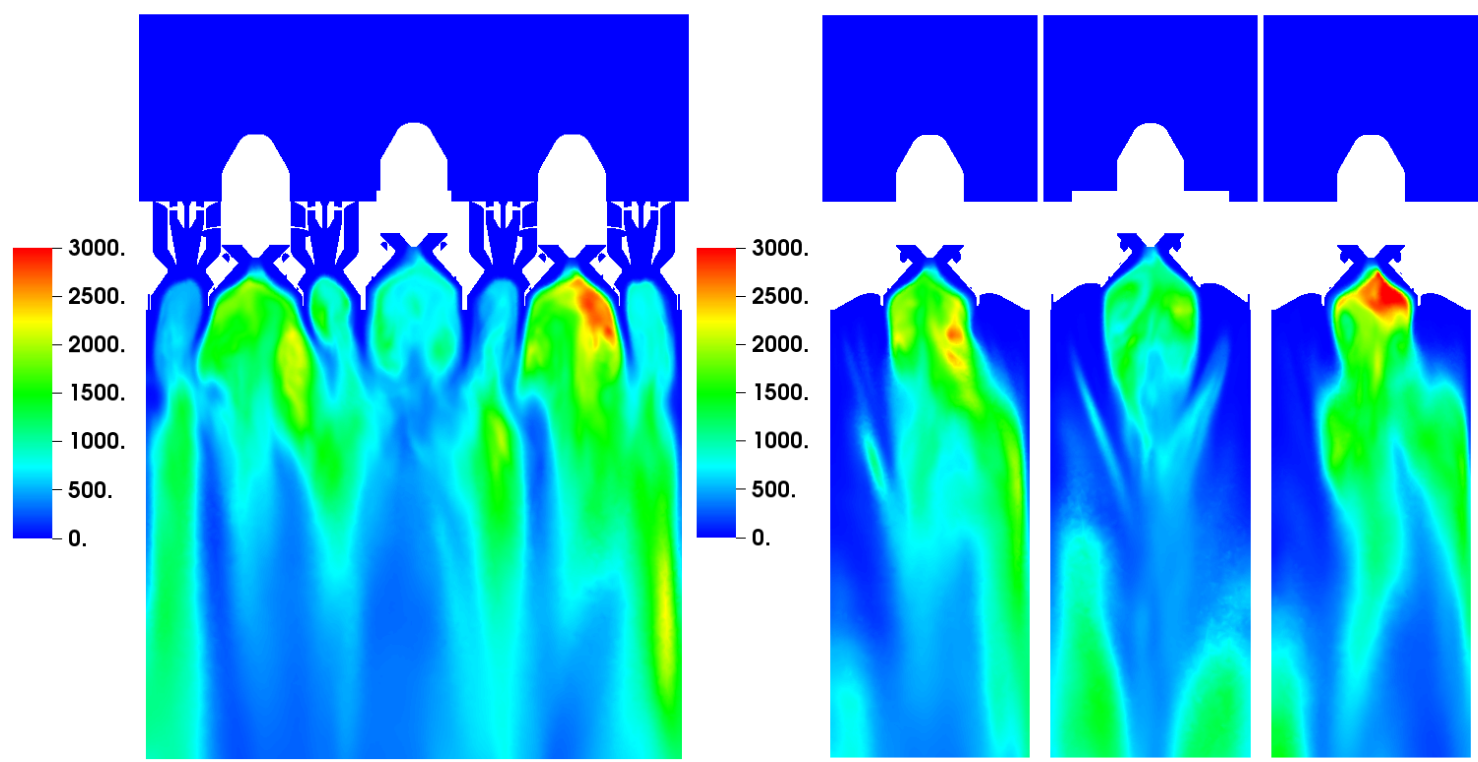

Figure 10. NO (ppm) contours at several cross sections for LDI-3 (left: horizontal slice along length of flametube, AA; right: vertical slices through each pilot injector, DD, BB, CC)

Contours of axial velocity at four axial locations were plotted to gain a better understanding of the aerodynamics and the mixing behavior of the flow. Figure 11 shows these cross-sectional contours at the dome face $(0 \mathrm{~mm})$, and at $25 \mathrm{~mm}, 50 \mathrm{~mm}$ and $150 \mathrm{~mm}$ downstream of the dome (exit plane of computational domain). The dome face $(0 \mathrm{~mm})$ plane shows very distinct differences in the size and strength of the CRZs between the 5-element central cup and its two adjacent 7-element cups. These differences can help explain the differences in flame structure behind the pilot of the 5element and 7-element cups described earlier (figure 9). The CRZs behind all the main injectors, being relatively weaker than the pilot CRZs, dissipate rapidly at the $25 \mathrm{~mm}$ location, and the flow is fairly well-mixed $50 \mathrm{~mm}$ downstream of the dome, and completely mixed at the exit plane (150mm downstream),
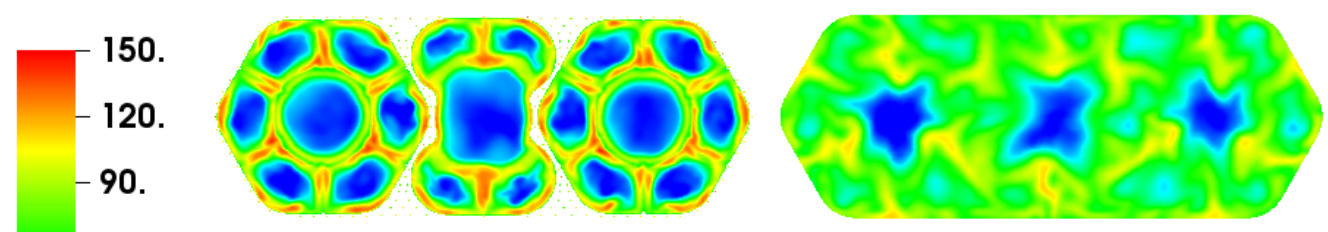

60.

-30 .

0.

-30 .
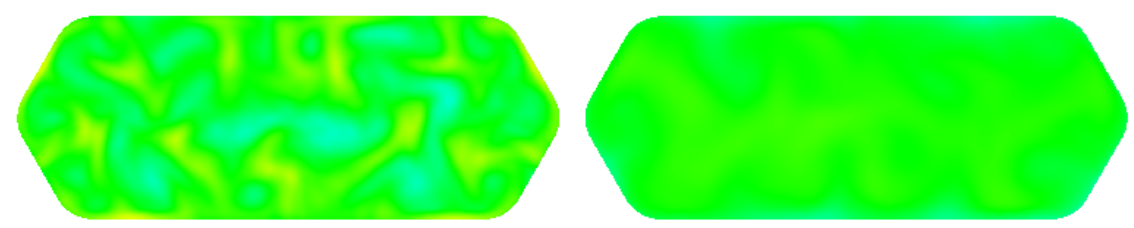

Figure 11. Axial Velocity (m/s) contours at four axial locations from dome face (upper left: 0mm; upper right: 25mm; lower left: $50 \mathrm{~mm}$; lower right: $150 \mathrm{~mm}$ or exit plane)

Figures 12 and 13 show contours of temperature and NO mass-fraction at a location 150mm downstream of the dome, which corresponds to the data-measurement probe-location of NASA's CE-5 experiment [Tacina 2017]. A massweighted area-average of exit temperature (T4) and NO was calculated from the time-averaged solution over the final flow-through cycle ( $2.6 \mathrm{~m}$-s computational time). The CFD predictions of T4 and EINOx for the baseline case were $2155 \mathrm{~K}$ and 34 , respectively (baseline $\mathrm{T} 3=920 \mathrm{~K}$, dome phi $=0.56$ with $24 \%$ cooling air, T4 (adiabatic) $=2085 \mathrm{~K}$, experimental (extrapolated) EINOx $=40$ ). The CFD predictions for the baseline case were in reasonable agreement with experimental data, which provided confidence and impetus to attempt a second set of computations for an 'offdesign' condition with $15 \%$ cooling air, dome phi $=0.5$. The CFD prediction of 26 for EINOx for the 'off-design' case 
agreed very well with the experimental (extrapolated) EINOx $=25$. The success of the current computational models in predicting emissions trends for supersonic cruise conditions, can thus point to the use of OpenNCC CFD as a reasonably well-anchored tool to support further CST design and analysis efforts.

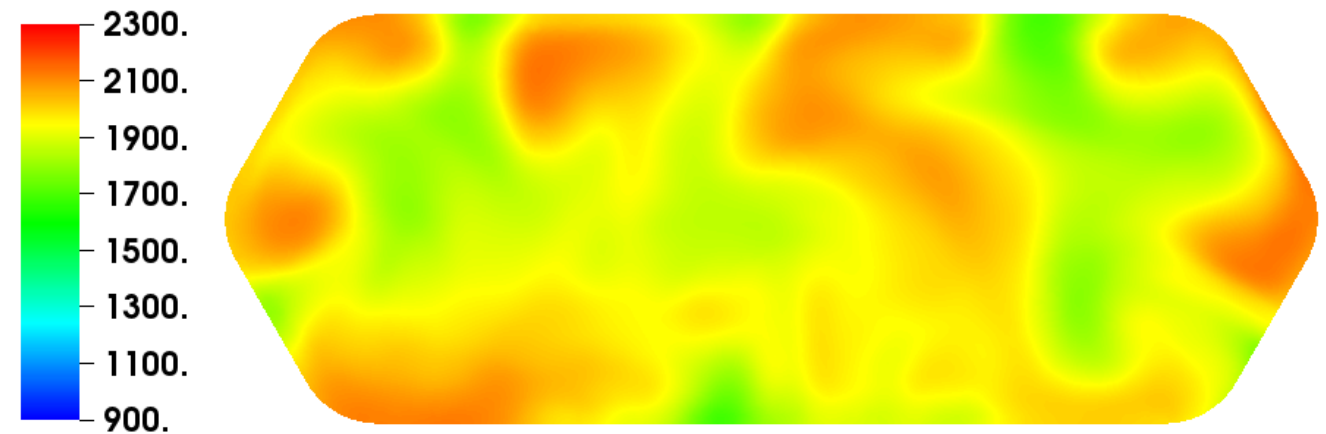

Figure 12. Temperature $(\mathrm{K})$ contours at $150 \mathrm{~mm}$ from dome face (exit plane)

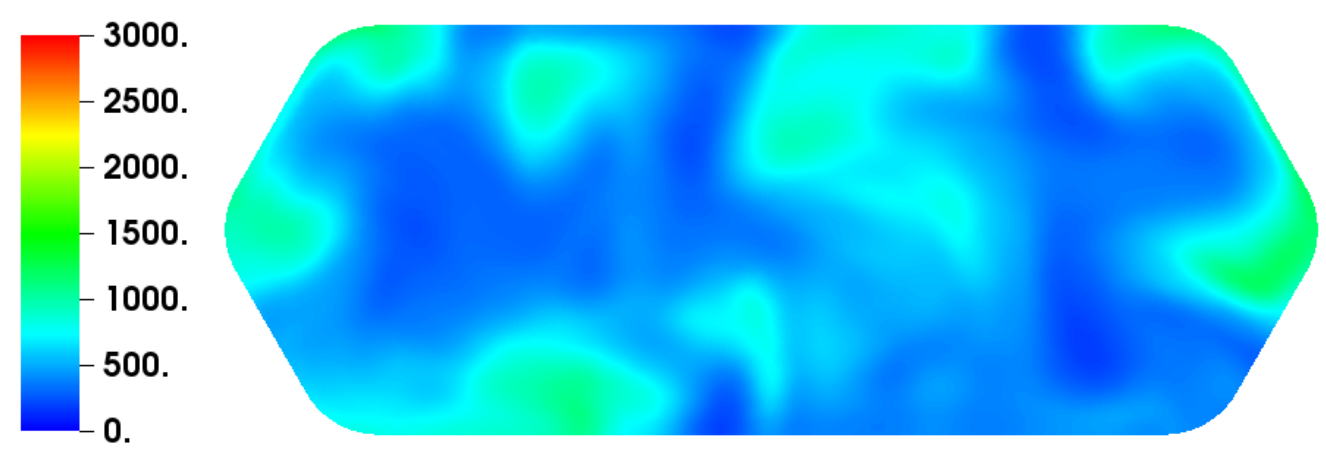

Figure 13. NO (ppm) contours at $150 \mathrm{~mm}$ from dome face (exit plane)

\section{SUMMARY AND FUTURE WORK}

The National Combustor Code (OpenNCC) was used to perform CFD evaluations of two different Lean-Direct Injection (LDI) combustor flame-tube arrays designed for NASA's N+2 (LDI-2) and N+3 (LDI-3) program efforts by Woodward, FST Inc. (WFST). Multi-phase reacting flow simulations were performed at cruise conditions of a supersonic cycle formulated at NASA Glenn Research Center. Both the LDI-2 and LDI-3 flame-tube arrays were predicted to have similar EINOx supersonic cruise emissions in the range of 25 to $35 \mathrm{~g} / \mathrm{kg}$ of fuel. The CFD results suggest that the current designs, which have been optimized to meet performance and emissions goals for subsonic operating conditions, can be used to meet CST program combustor goals with a few changes in injection element layout and injector component design. Injector component redesign should focus on evaluation the effect of replacing the simplex fuel nozzles with airblast or air-assist fuel nozzles, which could have a first-order effect on NO production at cruise conditions. In addition, variations in injection element layout (recessing pilot and injectors, changing the airswirler orientations of pilot and main injectors) could be easily evaluated with OpenNCC CFD, to derive performance and emissions optimized LDI configurations to meet CST program goals.

\section{ACKNOWLEDGEMENTS}

This work was funded by NASA's Commercial Supersonics Technology (CST) Program. Computational resources were provided by the NAS Supercomputing Facility at NASA Ames. 


\section{REFERENCES}

1. Morgenstern, J., Norstrud, N., Jack Sokhey, Steve Martens, and Juan J. Alonso, “Advanced Concept Studies for Supersonic Commercial Transports Entering Service in the 2018 to 2020 Period, Phase I Final Report," NASA/CR2013-217820.

2. Morgenstern, J., Buonanno, M., Yao, J., Murugappan, M., Paliath, U., Cheung, L., Malcevic, I., Ramakrishnan, K., Pastouchenko, N., Wood, T., Martens, S., Viars, P., Tersmette, T., Lee, J., Simmons, R., Plybon, D., Alonso, J., Palacios, F., Lukaczyk, T. and Carrier, G., "Advanced Concept Studies for Supersonic Commercial Transports Entering Service in the 2018-2020 Period, Phase 2," NASA/CR-2015-218719.

3. Reddy, D. R. and Lee, C-M, An Overview of Low-Emission Combustion Research at NASA Glenn, ASME Turbo Expo 2016: Turbomachinery Technical Conference and Exposition GT2016; 13-17 Jun. 2016; Seoul S. Korea; Paper GT2016-56100

4. Ashcraft, Scott W., Padron, Andres S., Pascioni, Kyle A., Stout, Gary W., Jr., Huff, Dennis L., "Review of Propulsion Technologies for N+3 Subsonic Vehicle Concepts," NASA/TM-2011-217239.

5. Tacina, K. M., Podboy, D. P., He, Z. J., Lee, P., Dam, B. and Mongia, H., A Comparison of Three Secondgeneration Swirl-Venturi Lean Direct Injection Combustor Concepts, 52nd AIAA/SAE/ASEE Joint Propulsion Conference, AIAA Propulsion and Energy Forum, Salt Lake City UT (AIAA 2016-4891)

6. Tacina, K.M., Podboy, D.P., Lee, P., and Dam, B., "Gaseous Emissions Results from a Three-Cup Flametube Test of a Third-Generation Lean Direct Injection Combustor Concept”, ISABE 2017, Edinburgh UK.

7. Ajmani, K., Mongia, H.C. and Lee, P., “CFD Evaluation of a 3rd Generation LDI Combustor," AIAA Paper 20175017, 53rd AIAA Joint Propulsion Conference, July 2017, Atlanta GA.

8. Ajmani, K., Mongia, H. C., and Lee, P., "CFD computations of emissions for LDI-2 combustors with simplex and airblast injectors", AIAA Paper 2014-3529, 50th AIAA Joint Propulsion Conference, July 2014.

9. Raju, M. S., “LSPRAY-IV: A Lagrangian Spray Module,” NASA CR-2012-217294.

10. Ajmani, K., Kundu, K., and Yungster, S., "Evaluation of Reduced Mechanisms for Combustion of Jet-A in LDI Combustor CFD Calculations," AIAA Paper 2014-3662, AIAA Propulsion and Energy Conference, Cleveland, OH, July 2014. 